\title{
DISCUSSION
}

\section{Influence of roundness on the void ratio and strength of uniform sand}

\author{
P. C. ROUSÉ, R. J. FANNIN and D. A. SHUTtLE (2008). Géotechnique 58, No. 3, 227-231
}

\section{P. Smart, Glasgow University}

It was encouraging to see the success achieved by the authors in using the traditional measure of roundness, that is, radius of corner normalised by radius of inscribed circle. However, it was disappointing to see that it had been necessary to inscribe the circles manually, because this method of measurement was automated over ten years ago, and at least four accounts are in the public domain (Luo et al., 1995; Luo, 1995; Luo, 1998; Smart, 2007).

Using an automatic image analyser would make it easy to compare the use of the circumcircle instead of the inscribed circle with a view to progressing to a three-dimensional analysis. Further, in pedology, it is traditional to consider also the ratio of the principal radii of gyration (or of the principal Feret diameters); and it would be interesting to learn whether the use of this additional measurement would be worthwhile.

\section{Authors' reply}

The authors thank the discusser for his interest in their finding that grain shape offers the potential for a unified relation between the maximum and minimum void ratio and angle of friction, in uniform gradations of sand. Given this finding, the authors concluded the influence of roundness appears sufficient to warrant its reporting in experimental studies on a routine basis and that it be calculated, rather than inferred from charts.

The authors calculated the roundness with reference to circles inscribed manually, however there is no need for disappointment at this approach. Our calculation was made from micrograph images for 30 randomly selected grains of
Badger sand and the manual approach was fully justified by insights gained to understanding the shape of this sand. We recognise there are advanced tools and techniques for automating the acquisition of grain images and also for calculating values of roundness; however, given the specific focus of our study, there was no compelling reason to use an automated approach.

We calculated the traditional measure of roundness (equation 1) for Badger sand so that the result could be compared directly with a database of values that we compiled from the literature (Table 1). Recall, the objective of this study was to combine three index properties of the material, $e_{\min }, e_{\max }$ and roundness, in a single unified plot. We concur with the discusser's general observation that alternate measures of roundness may be equally worthwhile, or indeed superior, to the traditional measure of roundness, and that progress to a three-dimensional analysis might also prove beneficial. Accordingly, we hope that our finding will encourage more investigation of the phenomenon.

\section{REFERENCES}

Luo, D. (1995). Image processing and pattern recognition applied to soil structure. $\mathrm{PhD}$ thesis, University of Glasgow.

Luo, D. (1998). Pattern recognition and image processing. Chichester: Horwood.

Luo, D., Smart, P. \& Macleod, J. E. S. (1995). Circular Hough transform for roundness measurement of objects. Pattern Recognition 28, No. 11, 1745-49.

Smart, P. (2007). Image analysis. Glasgow: Glasgow University Press. 